\title{
Visualizing the Software Metrics of State chart Diagram using Program Slicing
}

\author{
Lavleen Kambow \\ Department of Computer Science Engineering \\ Guru Nanak Dev Engineering College, Ludhiana \\ Punjab, India.
}

\author{
Daljeet Singh \\ Department of Computer Science Engineering \\ Guru Nanak Dev Engineering College, Ludhiana \\ Punjab, India.
}

\begin{abstract}
This paper proposes a new technique for the measurement of ACOS and ASSOS of the Statechart diagram using Program Slicing. The Statechart diagram contains the dynamic information of the Object-Oriented system. In this research work, State Dependency Graph (STDG) is generated from the Criteria table of the Statechart diagram. Then, the STDG is dynamically sliced, which results easy understandability of statechart diagram for an effective communication among the developers. These slices can be further used to measure accurate ACOS represents cohesion \& ASSOS represents coupling, from values of COS and SS respectively. The objective of this new approach is to measure the accurate results of ACOS and ASSOS in contrast to the previous research.
\end{abstract}

\section{General Terms}

Criteria Table, state dependency graph, dynamic slicing.

\section{Keywords}

Statechart Diagram, Program Slicing, Cohesiveness of states, similar states, Average Cohesiveness of States, Average Number of Similar States of States.

\section{INTRODUCTION}

A state diagram used to model dynamic nature of a system and describes a state machine. It basically deals with different states of an object during its lifetime so describes the flow of control from one state to another state. These states are changed in respond to certain external or internal events. In fig 1 the state diagram [1] is showing the behavior of a light system with the five different states (1, 2, 3, 4, and 5). Each state represents the state of an object with different value of brightness and ON or OFF semantic [1].

\section{RELATED WORK}

For evaluating understandability of the statechart diagram, semantic based Cohesion and Coupling has been proposed in [1] and slicing of State-based Models has been proposed in [8], [5], [9]. Data dependence for Slicing Statechart and data dependence from Statechart is given in [6], [7], which describes the dependence graph in a better way. Defining and validating Metrics for UML Statechart has been described in [4]. In the coming parts of this paper, first draw a state dependency graph , then apply slicing technique over graph , then calculate COS and SS, further apply ACOS and ASSOS metrics over the sliced parts and observe and comparing the results.

\section{STATE DEPENDENCY GRAPH 3.1 Statechart Diagram}

Fig 1 shows the Statechart diagram of a Behavior of a light system. Now we have to draw its state dependency graph by following criteria given below in table [1]. In this Statechart Diagram, we have two semantics like ON, OFF with corresponding $(b=1,2,3$; bright $=1,2,3)$ event fired on a state then it moves to another state. Figure is taken from [1].

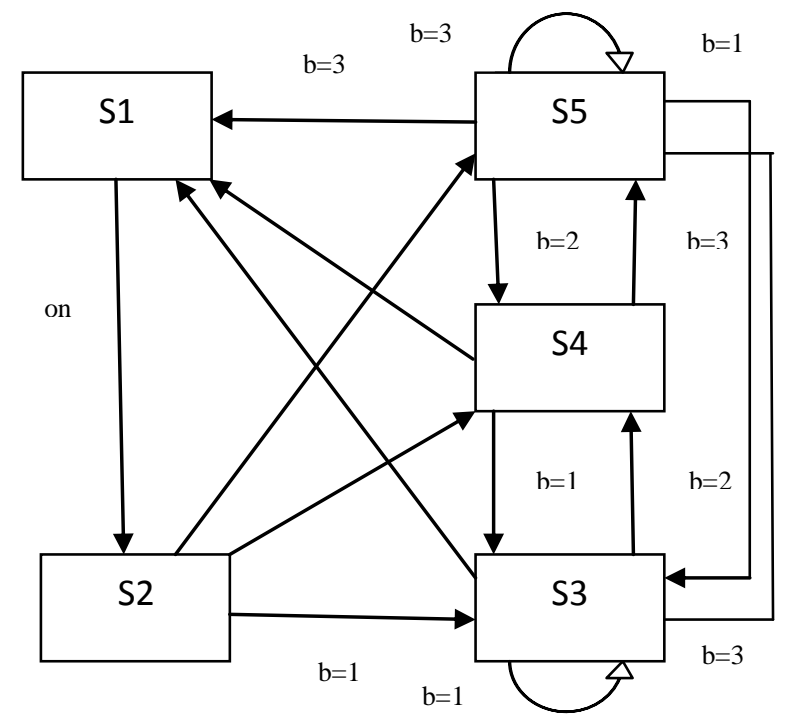

Fig 3: Statechart diagram of light system

\subsection{Draw a Criteria table for STDG}

In above Table, we have two semantics ON and OFF, When an event is fired on state of an object with appropriate event value like $b=1,2,3$ or bright $=1,2,3$, then it moves to next state, [7] following the above criteria table, we can draw the State Dependency Graph (STDG) [6], [7]. 
Table 1: A Criteria table

\begin{tabular}{|c|c|c|c|}
\hline Semantic & Event & State & $\begin{array}{l}\text { Next } \\
\text { State }\end{array}$ \\
\hline \multirow[t]{11}{*}{$\mathrm{ON}$} & $\mathrm{b}=1$ & S2 & S3 \\
\hline & & S3 & S3 \\
\hline & & S4 & S3 \\
\hline & & S5 & S3 \\
\hline & $\mathrm{b}=2$ & S3 & S4 \\
\hline & & S5 & S4 \\
\hline & & S3 & S5 \\
\hline & $b=3$ & S5 & S5 \\
\hline & & S2 & S5 \\
\hline & & S3 & S5 \\
\hline & & S4 & S5 \\
\hline \multirow[t]{3}{*}{$\overline{\mathrm{OFF}}$} & bright $=1$ & S3 & S1 \\
\hline & bright $=2$ & S4 & S1 \\
\hline & bright $=3$ & S5 & S1 \\
\hline
\end{tabular}

\subsection{Draw a final STDG}

Draw a STDG by following the criteria table [7]. A state will be represented by a circle and dependencies will be shown by directed edges between the circles [6], [7]. By following the criteria table of the Statechart Diagram, we can draw a state dependency graph shown in figure 2. In state dependency graph, we have five states s1, s2, s3, s4, s5 and corresponding dependencies can be shown by the directed edges between

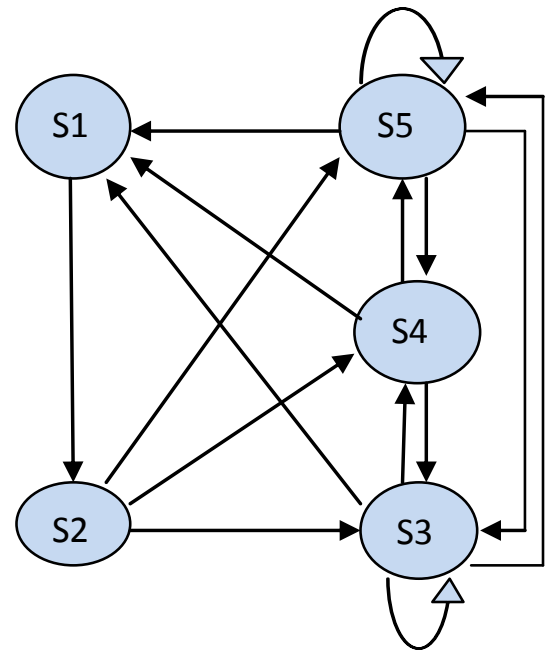

States. Fig 2: State Dependency Graph (STDG)

\section{DYNAMIC SLICING OF STDG}

A slicing technique is basically used to facilitate the process of testing and debugging [8], [5], [9]. There are two types of Slicing like Static slicing and dynamic slicing. A static slicing is formed by eliminating those parts of the program that are not relevant to the values stored in the selected set of variables at the selected point of interest. A dynamic slice is regarding with finding all statements that can affect its value for the current input, instead of all the statements that could influence the value of the variable for any inputs [9]. In this paper we have applied the dynamic slicing because the state of the object in these types of diagram is continuously changing[8], [5]. Dynamic slices of the State Dependency Graph are shown in figure 3
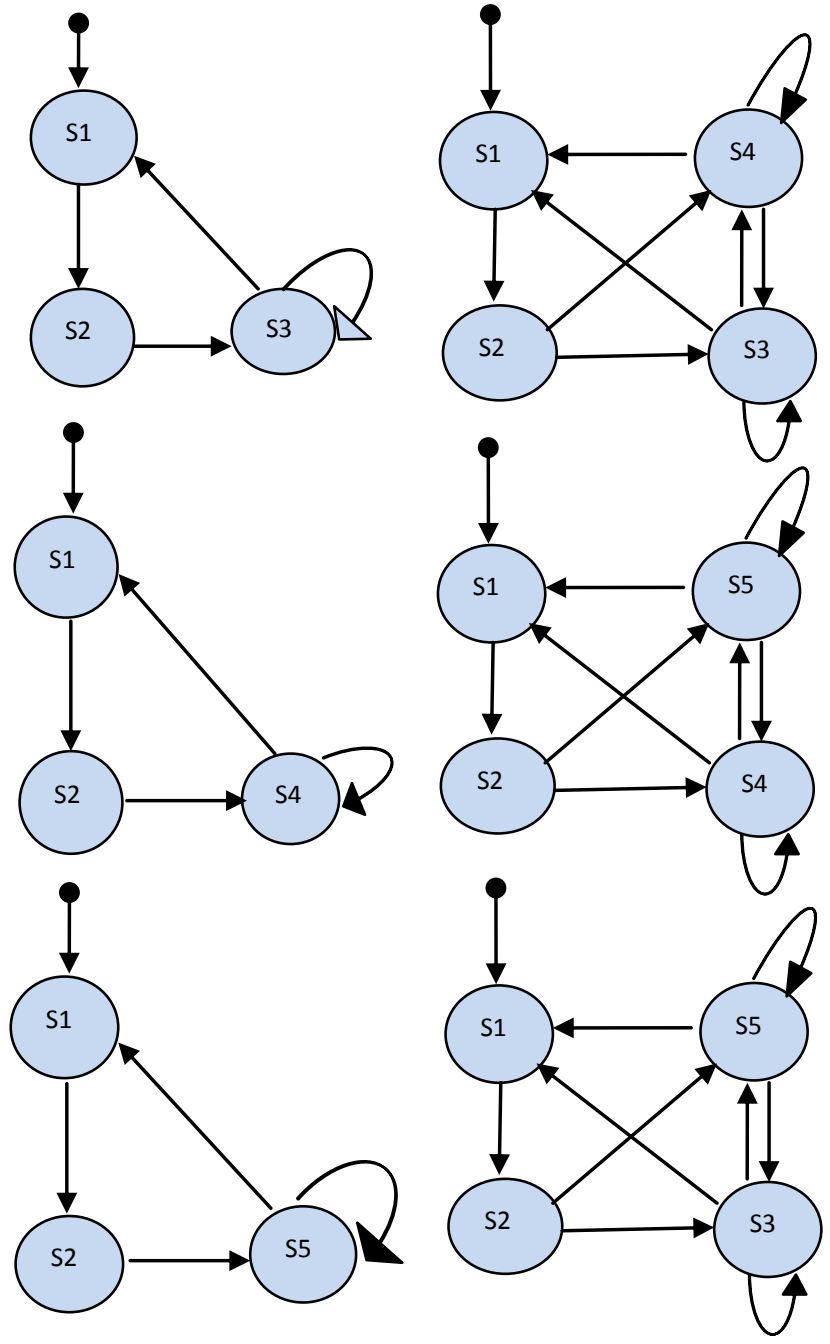

Fig 3: Dynamic Slices of STDG

\section{VARIOUS CONCEPTS}

\subsection{Cohesiveness of a State (COS)}

Cohesiveness of a state (s) is denoted by $\operatorname{COS}(\mathrm{s})$. When a state has more than one semantic then there will be less cohesiveness of a state corresponding understandability of a state will less and vice versa [1].

$\operatorname{COS}(\mathbf{s}):=1 /|\operatorname{SEM}|$ 


\subsection{Similar States (SS)}

Two states S1, S2 are similar, when both have same start state and event, have one or more incoming transitions and one or more outgoing transitions, have one or more outgoing transitions, respectively, then $\mathrm{S} 1$ and $\mathrm{S} 2$ are similar states [1].

\section{CAlCulating ACOS}

Average Cohesiveness of States [1]

$$
\operatorname{ACOS}(\mathbf{S D})=\sum \operatorname{COS}(\mathbf{s}) /|\mathbf{S}|,
$$

$\mathrm{S}$ is no of states of a state diagram [1]. When all the states of a State Diagram have only one semantic then cohesion of each state of SD will be 1, then ACOS will be 1 [1]. In Table 2, first, we have calculated the value of COS of different states of a slice, like COS of states s1, s2, s3 for slice 1, second, have calculated the values of ACOS form values of COS of different slices [3].

Table 2: Calculate COS and ACOS

\begin{tabular}{|c|c|c|}
\hline Slices & COS & ACOS \\
\hline Slice 1 & $\operatorname{COS}(\mathrm{s} 1)=1 \operatorname{COS}(\mathrm{s} 2)=1$ & \\
& $\operatorname{COS}(\mathrm{s} 3)=1$ & $3 / 3=1$ \\
\hline Slice 2 & $\operatorname{COS}(\mathrm{s} 1)=1 \operatorname{COS}(\mathrm{s} 2)=1$ & \\
& $\operatorname{COS}(\mathrm{s} 4)=1$ & $3 / 3=1$ \\
\hline Slice 3 & $\operatorname{COS}(\mathrm{s} 1)=1 \operatorname{COS}(\mathrm{s} 2)=1$ & \\
& $\operatorname{COS}(\mathrm{s} 5)=1$ & $3 / 3=1$ \\
\hline Slice 4 & $\operatorname{COS}(\mathrm{s} 1)=1 / 3, \operatorname{COS}(\mathrm{s} 2)=1$ & \\
& $\operatorname{COS}(\mathrm{s} 3)=1, \operatorname{COS}(\mathrm{s} 4)=1$ & $(3+0.33) / 4=0.83$ \\
\hline Slice 5 & $\operatorname{COS}(\mathrm{s} 1)=1 / 3, \operatorname{COS}(\mathrm{s} 2)=1$ & \\
& & \\
& $\operatorname{COS}(\mathrm{s} 4)=1, \operatorname{COS}(\mathrm{s} 5)=1$ & $(3+0.33) / 4=0.83$ \\
\hline Slice 6 & $\operatorname{COS}(\mathrm{s} 1)=1 / 3, \operatorname{COS}(\mathrm{s} 2)=1$ & \\
& $\operatorname{COS}(\mathrm{s} 3)=1, \operatorname{COS}(\mathrm{s} 5)=1$ & $(3+0.33) / 4=0.83$ \\
\hline
\end{tabular}

\section{CALCUlate aSSOS}

Average Number of Similar States of States [1] $\operatorname{ASSOS}(\mathbf{s}):=\sum|\mathbf{S S}(\mathbf{s})| /|\mathbf{S}|$

$\mathbf{S}$ is a no of states of a state diagram. When each state represents different semantics, then value of ASSOS will be 0 [1]. In Table 3, first, we have calculated the value of SS of different states of a slice, like ASSOS of states s1, s2, s3 for slice 1, second, have calculated the values of ASSOS form values of SS of different slices [3].

Table 3: Calculate SS and ASSOS

\begin{tabular}{|c|c|c|}
\hline Slices & SS & ASSOS \\
\hline Slice 1 & $\mathrm{SS}(\mathrm{s} 1)=0, \mathrm{SS}(\mathrm{s} 2)=1$ & $2 / 3=0.667$ \\
& $\mathrm{SS}(\mathrm{s} 3)=1$ & \\
\hline
\end{tabular}

\begin{tabular}{|c|c|c|}
\hline Slice 2 & $\begin{array}{c}\mathrm{SS}(\mathrm{s} 1)=0, \mathrm{SS}(\mathrm{s} 2)=1 \\
\mathrm{SS}(\mathrm{s} 4)=1\end{array}$ & $2 / 3=0.667$ \\
\hline Slice 3 & $\begin{array}{c}\mathrm{SS}(\mathrm{s} 1)=1 \mathrm{SS}(\mathrm{s} 2)=1 \\
\mathrm{SS}(\mathrm{s} 5)=1\end{array}$ & $2 / 3=0.667$ \\
\hline Slice 4 & $\begin{array}{l}\mathrm{SS}(\mathrm{s} 1)=0, \mathrm{SS}(\mathrm{s} 2)=0 \\
\mathrm{SS}(\mathrm{s} 3)=1, \mathrm{SS}(\mathrm{s} 4)=1\end{array}$ & $2 / 4=0.5$ \\
\hline Slice 5 & $\begin{array}{l}\mathrm{SS}(\mathrm{s} 1)=0, \mathrm{SS}(\mathrm{s} 2)=0 \\
\mathrm{SS}(\mathrm{s} 4)=1, \mathrm{SS}(\mathrm{s} 5)=1\end{array}$ & $2 / 4=0.5$ \\
\hline Slice 6 & $\begin{array}{l}\mathrm{SS}(\mathrm{s} 1)=0, \mathrm{SS}(\mathrm{s} 2)=0 \\
\mathrm{SS}(\mathrm{s} 3)=1, \mathrm{SS}(\mathrm{s} 5)=1\end{array}$ & $2 / 4=0.5$ \\
\hline
\end{tabular}

\section{COMPARTIVE STUDY OF RESULTS}

We have calculated the values of ACOS and ASSOS of the different slices of state dependency graph of a Statechart diagram shown in fig 1 . Here, values resulted are more accurate than previously calculated in [1]. Here, calculated value of ACOS is 0.915 which is more than previously calculated ACOS value 0.85 in [1], which shows the more cohesiveness of states of the Statechart Diagram. Calculated value of ASSOS is 0.58 according to our criteria followed through Program Slicing, which is less than previously calculated ASSOS value 1.2 in [1], which shows less coupling among the states of the Statechart Diagram

Table 4: Compartive study of results

\begin{tabular}{|c|c|}
\hline $\begin{array}{c}\text { Current/Previous } \\
\text { Research }\end{array}$ & Values of ACOS and ASSOS \\
\hline $\begin{array}{c}\text { Current Researched } \\
\text { ACOS }\end{array}$ & Average ACOS $=5.49 / 6=0.915$ \\
\hline $\begin{array}{c}\text { Current Researched } \\
\text { ASSOS }\end{array}$ & Average ASSOS $=3.51 / 6=0.58$ \\
\hline $\begin{array}{c}\text { Previous Researched } \\
\text { ACOS }\end{array}$ & 0.85 \\
\hline $\begin{array}{c}\text { Previous Researched } \\
\text { ASSOS }\end{array}$ & 1.2 \\
\hline
\end{tabular}

\section{CONCLUSION}

For the more understandability of the system, there should be high value of cohesion and less value of coupling, a system with more understandability, facilitates the easy maintenance, because of fewer interactions of states with each other which consequently increases the reusability of the system. In this paper, we have calculated accurate values of ACOS and ASSOS, in which, there is low value of ASSOS represents low cohesion means less interactions between states and high value of ACOS represents high cohesion means self contained functionality. Using our approach using dynamic slicing, resulted values have more accuracy than previous researched values of ACOS and ASSOS in [1]. Our approach, using dynamic slicing, facilitates easy the understandability of statechart diagrams. 


\section{FUTURE SCOPE}

In future, this Approach can be used for calculating the value of cohesion and coupling using program slicing over the various types of the UML diagrams to analyze the static and dynamic aspects of the system.

\section{REFERENCES}

[1] Green, P., Lane, P. C.R., Rainer, A. 2009 An introduction to Slice-Based Cohesion and Coupling Metrics. School of Computer Science, University of Hertfordshire, Vol. 488, 3

[2] Miranda, D., Genero, M., Piattini, M., 2003 Empirical validation of metrics for UML Statechart diagram. ALARCOS research group, Department of computer sciences, university of Castilla La-Mancha.

[3] Samuel, P., Mall, R. 2008 A novel test case design technique using dynamic slicing of UML Sequence Diagrams. E-informatica Software Engineering Journal

[4] Fox, C., Luangsodsai, A., 2006 And-Or Dependence graphs for Slicing statecharts. Department of Computer Science University of Essex

[5] Kim, H. J., Bae, D. H., Debroy, V., Wong, W. E. 2011 Deriving Data Dependence from/for UML State Machine Diagrams. Fifth International Conference on Secure Software Integration and Reliability Improvement
[6] Korel, B., Singh, I., Tahat, L., Vaysburg, B., 2003 Slicing of State-Based Models. Proceedings of the International Conference on Software Maintenance (ICSM'03)

[7] Sward, D.R.E., Chamillard, D.R.T., Cook, D.D.A. 2004 Using Software Metrics and program slicing for refactoring. The Journal of defense software engineering.

[8] Mohsin, Shaikh., Kaleem, Zeeshan, 2010, Program Slicing Based Software Metrics towards code Restructuring, Second international conference on Computer Research and Development, pp. 738-741.

[9] Swain, S. K. , Mohapatra, D. P. and Mall, R. 2010. Test

[10] case generation based on state and activity models. Journal of Object Technology, 9(5), pp. $1-27$

[11] Blanco, R. , Fanjul, J. G. and Tuya, J., 2010, Test case generation for transition-pair coverage using Scatter Search. International Journal of Software Engineering and Its Applications Vol. 4, No. 4.

[12] Krishnan, Hema, Samuel, Philip., 2010, Relative Extraction Methodology for Class Diagram Generation using Dependency Graph, ICCCCT, Vol. 10, 1, pp. 815-820 